\title{
PERANCANGAN SISTEM APLIKASI PERSEDIAAN PENJUALAN DAN PEMBELIAN BERBASIS JAVA DI APOTEK ANDA
}

\author{
Risnah Mayliana $^{1}$, V.H Valentino ${ }^{2}$, Nurullaeli ${ }^{3}$ \\ ${ }^{1,2}$ Universitas Indraprasta PGRI \\ Jalan Raya Tengah, Gedong, Pasar Rebo, Jakarta Timur, Daerah Khusus Ibu Kota Jakarta 13760 \\ ․ㅡisnahmayliana30@gmail.com, ${ }^{2}$ v.h.valentino.na70@gmail.com, ${ }^{3}$ leli.biofisika@gmail.com
}

\begin{abstract}
ABSTRAK
Sebuah sistem dapat membantu pekerjaan manusia yang sebelumnya dilakukan dengan cara manual. Pada apotek terdapat banyak data obat-obat, data pasien, dan transaksi lain yang dilakukan setiap harinya serta tidak mungkin dihafalkan begitu saja. Tujuan penelitian ini adalah merancang sistem yang dapat menyimpan data yang terdapat pada operasional kerja apotek. Dengan cara mengimplementasikan sebuah sistem ke dalam sistem kerja apotek diharapkan akan mempermudah pendataan yang selama ini bersifat manual. Dalam penelitian ini peneliti menggunakan metode penelitian Analytical Hierarchy Process (AHP) untuk menjelaskan sistem yang berjalan serta mempermudah dalam menganalisis dan pengambilan keputusan. Metode analisis yang peneliti lakukan adalah dengan mengadakan studi pustaka dan studi lapangan pada Apotek Anda. Peneliti mendapatkan hasil penelitian bahwa sistem aplikasi ini dapat mempermudah kegiatan transaksi penjualan serta pembelian agar lebih efektif dan efisien, melakukan transaksi penjualan serta transaksi pembelian, mengetahui total pembelian, dan penjualan dalam satu bulan. Simpulan dari penelitian yang dilakukan peneliti adalah dengan diimplementasikan aplikasi ini maka akan menyelesaikan permasalahan yang terdapat pada Apotek Anda yaitu memudahkan dalam pembuatan laporan penjualan, pembelian, dan persediaan barang.
\end{abstract}

Kata Kunci: Sistem Persediaan Penjualan dan Pembelian, Transaksi, Penelitian.

\begin{abstract}
A system can help human work that was previously done manually. In pharmacies there is a lot of data on medicines, patient data, and other transactions that are carried out every day and cannot be memorized just like that. The purpose of this study is to design a system that can store data contained in pharmacy work operations. By implementing a system into the pharmacy work system, it is hoped that it will facilitate data collection which has been manual so far. In this study, the researcher used the Analytical Hierarchy Process $(A H P)$ research method to explain the current system and make it easier to analyze and make decisions. The analytical method used by the researcher is to conduct a literature study and field study at your pharmacy. Researchers get research results that this application system can facilitate sales and purchase transactions to be more effective and efficient, conduct sales and purchase transactions, find out total purchases, and monthly sales. The conclusion from the research conducted is that by implementing this application, it will solve the problems contained in your pharmacy, namely making it easier to make reports on sales, purchases, and inventory.
\end{abstract}

Key Word: Sales and Purchase Inventory System, Transaction, Research.

\section{PENDAHULUAN}

Apotek merupakan suatu tempat tertentu, tempat dilakukan pekerjaan kefarmasian penyaluran perbekalan farmasi, perbekalan kesehatan lainnya kepada masyarakat, berdasarkan Keputusan Menteri Kesehatan No.1027/MenKes/SK/IX/2004 tentang Pelayanan Kefarmasian di Apotek (Purbasari, 2017).

Dalam bidang kesehatan apotek merupakan usaha yang melayani pembeli dengan menjual beberapa jenis obat, dalam kegiatan usaha nya apotek membutuhkan sebuah sistem yang dapat mengolah data demi memperlancar jalannya suatu usaha. Data obat-obatan, persediaan obat, transaksi pembelian serta penjualan obat tidak mungkin dapat dikontrol dengan sedemikian rupa jika cara kerjanya masih manual. Pengolahan data ialah suatu proses menerima data masukan (input) memproses (processing) menggunakan proses tertentu, dan mengeluarkan hasil proses data ke dalam bentuk informasi (output) (Mahyuni, Martono, 2014). Oleh karena itu, dibutuhkan sebuah sistem yang akan mempermudah pekerja dalam mengolah data persediaan obat, mempermudah dalam setiap aspek pekerjaan di apotek. Perbaikan yang peneliti akan lakukan adalah dengan menerapkan sistem 
berbasis komputer, secara keseluruhan untuk hal pendataan persediaan obat serta proses lain yang berkaitan dengan transaksi dan pencatatan pada apotek.

Tujuan dari penelitian ini ialah peneliti dapat menganalisis sistem yang sedang berjalan pada Apotek Anda yang nantinya akan menghasilkan sistem untuk menghitung serta memproses data penjualan dan pembelian obat pada Apotek Anda. Peneliti mendapatkan hasil penelitian bahwa sistem manajemen yang sedang berjalan pada Apotek Anda dilakukan secara konvensional ini akan memakan banyak waktu dan tenaga, belum termasuk kesalahan yang rentan terjadi (human error). Sistem informasi merupakan kumpulan dari perangkat keras dan perangkat lunak komput perangkat manusia yang akan mengolah data menggunakan perangkat keras dan perangkat lunak tersebut (Gozali, Gunadhi, \& Kurniawati, 2012). Adapun manfaatnya meningkatkan kinerja pegawai Apotek Anda, proses kerja yang dihasilkan akan lebih terstruktur, akurat, dan waktu pengerjaan menjadi lebih efektif.

\section{METODE PENELITIAN}

Dalam sebuah penelitian diperlukan suatu metode yang diharapkan sesuai dengan pokok permasalahan yang akan diteliti. Penelitian adalah suatu proses yang bertujuan untuk menemukan, mengembangkan, mencatat, dan menganalisis informasi data yang dilakukan dengan sabar, hati-hati, terencana, dan sistematis serta berdasarkan ilmu pengetahuan (Marzuki, 2015).

Peneliti menggunakan pendekatan kualitatif yaitu suatu metode penelitian yang bekerja berlandaskan kepada filsafat postpositivisme, digunakan untuk meneliti dengan kondisi objek yang sangat orisinil.

Metode yang mendukung dalam penelitian ini adalah metode Analytical Hierarchy Process (AHP) Proses Hirarki Analitik, yang dikembangkan oleh Thomas L. Saaty pada tahun 1986. Analytic Hierarchy Process (AHP) adalah analisis yang digunakan dalam pengambilan keputusan dengan pendekatan sistem, di mana pengambil keputusan berusaha memahami suatu kondisi sistem dan membantu melakukan prediksi dalam mengambil keputusan (Putri, 2012).
Analytic Hierarchy Process (AHP) adalah sebuah metode untuk memeringkat alternatif keputusan dan memilih yang terbaik dengan beberapa kriteria (Taylor, 2014). Analytical Hierarchy Process (AHP) dapat memudahkan peneliti dalam menganalisa dan mengambil suatu keputusan berdasarkan pertimbangan pendapat secara logis dari suatu permasalahan yang terjadi.

Pengambilan keputusan multikriteria dengan dukungan metodologi yang telah diakui dan diterima sebagai prioritas yang secara teori dapat memberikan jawaban yang berbeda dalam masalah pengambilan keputusan serta memberikan peringkat pada alternatif solusinya merupakan pengertian lain dari AHP (Tadeusz dan Kazibudzki, 2013).

Peneliti melakukan pengumpulan data informasi untuk mendukung penyempurnaan hasil dari penelitian ini yaitu antara lain:

\section{Studi Pustaka}

Peneliti melakukan studi pustaka yaitu dengan membaca serta mempelajari jurnal-junal dan buku-buku yang berhubungan erat dengan analisis serta perancangan sistem yang akan penulis kembangkan dalam penelitian ini. Peneliti melakukan studi dengan membuka website yang relevan dengan topik dalam penelitian ini.

\section{Observasi}

Observasi yang dilakukan peneliti dengan cara pengumpulan data dari pengamatan yang dilakukan secara langsung terhadap objek penelitian dalam rentan waktu tertentu. Melakukan pencatatan dengan sistematis mengenai hal yang sedang diamati oleh peneliti. Tujuan observasi yaitu untuk mengetahui secara langsung bagaimana proses manajemen proyek pada Apotek Anda. Hasil observasi digunakan peneliti untuk memperoleh data akurat dan relevan sesuai dengan tujuan dari penelitian.

\section{Wawancara}

Wawancara yang dilakukan peneliti merupakan teknik dari pengumpulan data dengan metode tanya jawab terhadap responden. Peneliti melakukan interview (wawancara) kepada pemilik usaha untuk mendapatkan informasi dan data yang lebih detail sebagai pertimbangan dalam mengambil kesimpulan dari penelitian. Pertanyaan yang diajukan seperti, bagaimana proses penjualan obat di Apotek Anda dan berapa rata-rata penjualan obat dalam satu bulan. 


\section{HASIL DAN PEMBAHASAN}

\section{Analisis Permasalahan}

Sistem diartikan sebagai sekelompok unsur yang erat hubungannya satu dengan yang lain, yang berfungsi bersama-sama untuk mencapai tujuan tertentu (Tata Sutabri, 2013). Setelah melakukan analisis terhadap sistem penjualan dan persediaan obat pada Apotek Anda yang sedang berjalan, dapat disimpulkan dari data yang ada bahwa terdapat beberapa permasalahan pada sistem. Berikut kelemahan dari sistem penjualan dan persediaan obat yang sedang berjalan, sebagai berikut:

1. Proses transaksi penjualan obat saat ini masih konvensional dan kurang baik, dilakukan dengan cara transaksi obat secara tertulis.

2. Di dalam proses pengolahan data obat dan pencatatan persediaan obat baik barang masuk ataupun keluar pada Apotek Anda terdapat kesalahan data karena pencatatan yang dilakukan masih bersifat manual atau disebut konvensional.

3. Dalam proses akhir pembuatan laporan obat masuk, penjualan obat, dan persediaan obat masih kurang detail, membutuhkan waktu yang lama dalam proses pembuatan laporan akhir, dikarenakan terlalu banyaknya bukti kwitansi atau nota pada Apotek Anda yang tersebar dan tidak tersusun dengan baik.

4. Sering terjadi kesalahan perhitungan uang dalam melakukan transaksi.

5. Pencarian data obat pada Apotek Anda masih menggunakan cara mencari satu persatu obat yang tersedia di rak obat/catatan daftar obat.

\section{Alternatif Penyelesaian Masalah}

Dari permasalahan yang dihadapi maka alternatif pemecahan masalah yang dapat diusulkan sebagai berikut:

1. Membuat aplikasi agar data otomatis sehingga akan meminimalisir kesalahan dan mempercepat proses transaksi pada Apotek Anda.

2. Pembuatan sistem penginputan data obat dan penjualan dengan lengkap, sehingga pada data laporan persediaan obat tidak terjadi ketidaksesuaian antara informasi yang ada dengan penjualan obat yang sebenarnya.

3. Dibuatnya sebuah aplikasi sistem yang terkomputerisasi untuk bisa mempercepat transaksi dalam menghitung harga obat sehingga proses perhitungannya akan lebih akurat dan cepat.

4. Media penyimpanan database juga tidak hanya memudahkan pengguna dalam menyimpan dan melakukan pencarian data, karena di sisi lain dapat memudahkan dalam pembuatan laporan akhir seperti laporan penjualan obat, laporan obat masuk, dan laporan persediaan obat. Dalam prosesnya pembuatan laporan akan lebih mudah dan cepat dengan adanya penyimpanan data dalam database.

\section{Aturan Bisnis Sistem Yang Diusulkan}

Prosedur yang berjalan pada sistem penjualan dan persediaan obat pada Apotek Anda masih menggunakan sistem yang konvensional. Dari teori penjualan merupakan aktivitas memperjualbelikan barang dan jasa kepada konsumen (Puspitawati, Lilis, 2010). Setelah peneliti melakukan penelitian dan merealisasi sistem yang akan diusulkan, perbedaan akan terlihat pada sistem yang lebih terkomputerisasi berbeda dengan sistem terdahulu yang masih manual pencatatan menggunakan kertas dan arsip. Berikut adalah prosedur dari sistem penjualan dan persediaan obat pada Apotek Anda:

1. Proses Pendataan Pemesanan Pasien: setiap pemesanan harus memiliki kode pemesanan pasien, data pemesanan pasien harus jelas.

2. Proses Pendataan Persediaan Obat: setiap obat harus memiliki kode obat, data obat harus jelas, dan mendata obat sesuai stok yang dimiliki.

3. Proses Pendataan Pembelian Obat: nota pembelian pemesanan obat harus sudah disetujui oleh apoteker pengelola Apotek Anda, supplier wajib memberikan faktur pembelian sebagai bukti pembelian, faktur pembelian dijadikan sebagai kode pembelian, data pembelian harus memiliki item barang, dan barang yang dibeli harus dalam kondisi baik.

4. Proses Pendataan Penjualan Obat: setiap penjualan harus memiliki kode yang tercetak pada struk penjualan, konsumen wajib mendapatkan struk pembelian, dan data penjualan harus sesuai dengan yang tertera pada struk penjualan.

5. Proses Laporan: asisten apoteker harus mencetak laporan persediaan obat dan pembelian obat setiap bulan untuk diserahkan kepada direktur operasional, 
kasir harus mencetak laporan pemesanan pasien dan penjualan obat setiap hari sebagai laporan penjualan perhari.

Berikut adalah dekomposisi dari sistem yang diusulkan oleh peneliti:

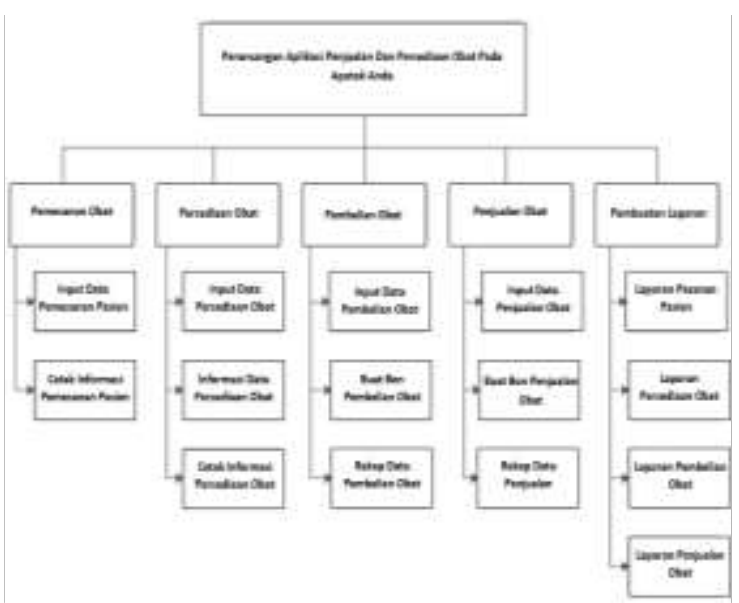

Gambar 1. Dekomposisi

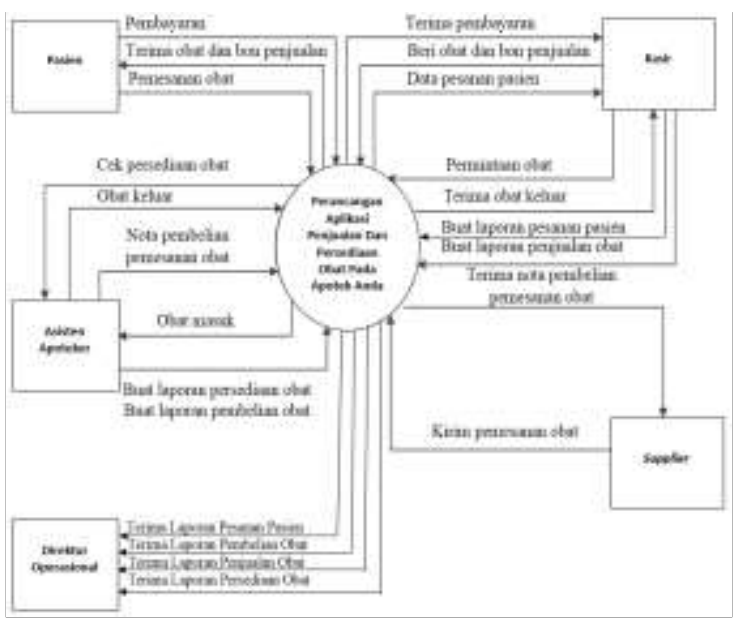

Gambar 2. DAD Konteks

\section{Tampilan Layar}

Berikut tahap implementasi dan pengujian pada sistem aplikasi program yang telah dibuat dengan menggunakan bahasa pemrograman java. Java adalah bahasa pemrograman untuk menciptakan isi yang aktif dalam halaman web, dan juga dapat dijalankan dalam semua komputer (Asropudin, 2013).

Berikut adalah beberapa tampilan layar dari implementasi sistem yang dibuat oleh peneliti dibuat dengan aplikasi Netbeans dengan bahasa pemrograman java. Tampilan layar didesain sedemikian rupa untuk memudahkan pengguna dalam menggunakan sistem, tampilan tidak menggunakan warna mencolok, dan disertai gambar agar pengguna tidak jenuh dalam menggunakan sistem. Gambar tampilan layar dan keterangan dapat dilihat seperti berikut ini:

\section{Tampilan Menu Utama}

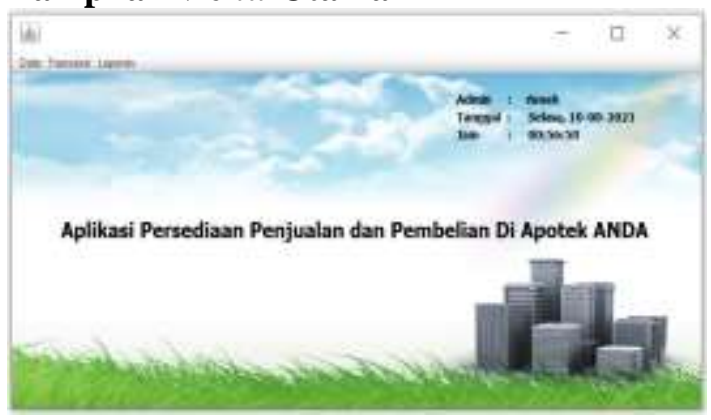

Gambar 3. Layar Utama

Tampilan halaman menu utama yang menampilkan menu bar untuk menampilkan menu-menu yang dibutuhkan oleh pengguna.

\section{Tampilan Menu Persediaan Obat}

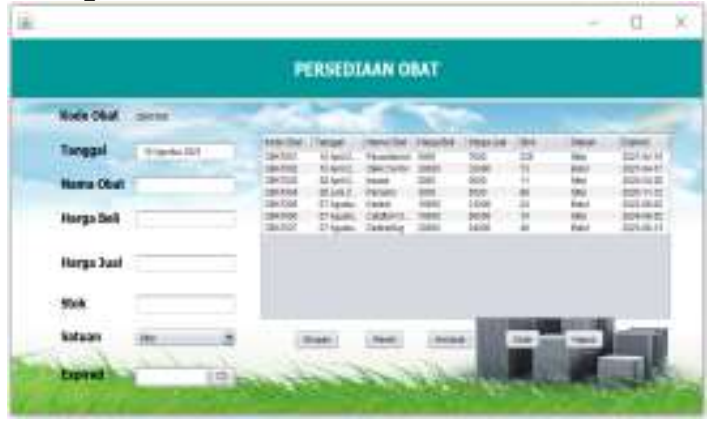

Gambar 3. Menu Persediaan Obat

Tampilan halaman menu persediaan obat yang menampilkan kolom untuk mengisi data stok obat.

\section{Tampilan Menu Data Supplier}

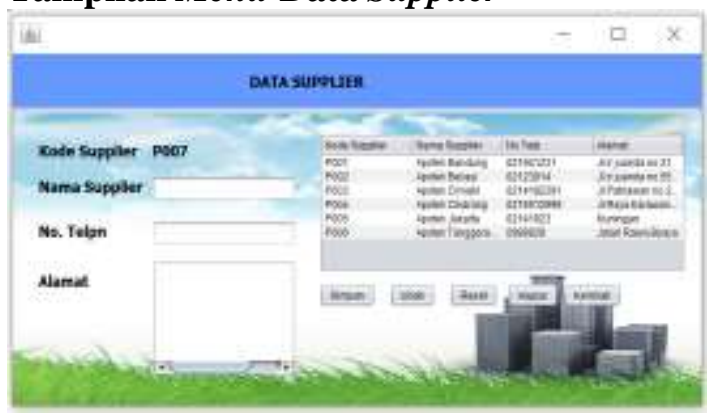

Gambar 4. Menu Data Supplier

Tampilan halaman menu data supplier yang menampilkan kolom untuk mengisi daftar supplier dari Apotek Anda. 
Tampilan Menu Laporan Data Persediaan Obat
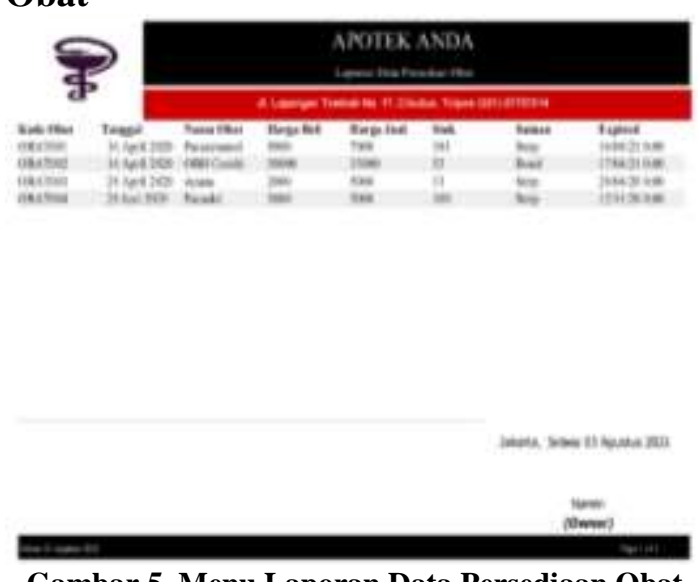

Gambar 5. Menu Laporan Data Persediaan Obat

Berisi laporan data persediaan obat dari Apotek Anda.

\section{SIMPULAN DAN SARAN}

Setelah peneliti menganalisa dari permasalahan sistem yang terdapat pada Apotek Anda, maka dapat diambil beberapa kesimpulan yaitu, dengan adanya sistem aplikasi ini akan membantu kegiatan transaksi penjualan dan pembelian agar lebih efektif dan efisien, dapat mengetahui total pembelian dan penjualan perbulan, dan juga aplikasi ini telah menggunakan database maka akan mempermudah dalam pembuatan laporan penjualan, pembelian, dan persediaan obat.
DAFTAR PUSTAKA

Asropudin, Pipin. (2013). Kamus Teknologi Informasi. Bandung: Titian Ilmu.

Gozali, L., Gunadhi, E., \& Kurniawati, R. (2012). Perancangan Sistem Informasi Penjualan Buku pada PD. Restu Percetakan. Jurnal Algoritma, 09(1), 211-219.

Mahyuni, Martono, S. (2014). Perancangan Sistem Pengolahan Data Pada SMA. Perancangan Sistem Pengolahan Data Pada Sma, 8(3), 180-187.

Marzuki. (2015). Metodologi Riset. Yogyakarta: PT Prasetia Widia Pratama.

Pawel Tadeusz and Kazibudzki1. (2013). On Some Discoveries in the Field of Scientific Methods for Management within the Concept of Analytic Hierarchy Process. International Journal of Business and Management. 8(8). 22-30.

Purbasari, Y. (2017). Rancangan Bangun Aplikasi Penjualan dan Persediaan Obat pada Apotek Merben di Kota Prabumulih. Jurnal Sistem Informasi dan Komputerisasi Akuntansi, 12(2), 2579-4477.

Puspitawati, Lilis, \& Anggadini, D. S.(2010). Sistem Informasi Akuntansi. Yogyakarta: Graha Ilmu.

Putri. (2012). Pemilihan Supplier Bahan Baku Pengemas dengan Metode AHP (Analytical Hierarchy Process). Jurnal Universitas Widyagama Malang, 20(1), 25-31.

Tata, Sutabri (2012). Analisis Sistem Informasi. Yogyakarta: Andi Offset.

Taylor, B.W. (2014). Introduction to Management Science. Jakarta: Salemba Empat. 